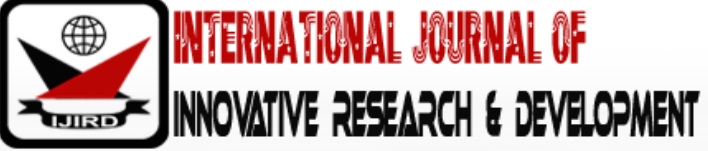

ISSN 2278 - 0211 (Online)

\section{Bonding at Glass / Steel Interface: A Precursor for Diverse Engineering Surfaces}

\author{
Philomena I. Chukwu \\ Associate Professor, Department of Pure and Industrial Chemistry, \\ Chukwuemeka Odumegwu Ojukwu University, Uli, Nigeria
}

\begin{abstract}
:
The interaction of silicate glass coating on steel was examined using Transmission Electron Microscope (TEM) Scanning Electron Microscope (SEM) and Energy Dispersive Atomic X-rays (EDAX). TEM and SEM micrographs displayed uniform graded interface as well as convoluted surfaces. The EDAX analysis identified the presence of Silica ( $\mathrm{Si}$ ) as the major components of the coating matrix in the ceramic layer and Iron ( $\mathrm{Fe}$ ) as the major component of the metal substrate in the metallic region. The interaction / dissolution of Si into the Iron matrix and that of Fe into the ceramic matrix at the interface are confirmed with EDAX. Consequently, bond formation / excellent adhesion of the silicate glass coating on the metal at the interface was generated. The product; a smooth surface with designed improved performance characteristics was formed.
\end{abstract}

Keywords: Glass coating, steel, interface, engineering surfaces

\section{Introduction}

Among numerous materials available for use by man, metals play the most crucial role in the advancement of human civilization and the development of human society as a whole. The business of metal to mankind is simply 'service' - service in various capacities, various quantities and various forms and shapes.

In this regard, iron and steel is considered the most widely used engineering constructional materials basically, because it can be manufactured cheaply in large quantities and in most precise specifications [Hawes, 1986]. Iron and steel contain well over $80 \%$ by weight of metallic alloys, in general use such as found in domestic appliances, transportation, industrial machinery, military hardware, on and off - oil shore explorations, space explorations etc. [Mailafia, 1998]

However, Iron and Steel when exposed to different service conditions corrode. The degradation of ferrous engineering materials in service conditions is not isolated but almost always part of a more complex process that involves physical and chemical environmental factors. Its effects on the structure and protective properties of the metal component are detrimental. The economic, legal and political aspects are just as important. The relatively low resistance of metal to corrosion can be largely ameliorated by the application of protective coatings such as glass coating.

Glass coating is a class of inorganic solids that are subjected to high temperature by manufacture. The product, an alkali borosilicate glass [Eppeler, 1986] to which ingredients appropriate to their application are added. The glass frit adheres to the steel substrate by fusion at high temperature, to give a glassy type of coating which bonds to the steel substrate through the formation of an interface.

When phases exist together, the boundary between the two of them is called the interface. The properties of the molecules forming an interface areoften a combination of the properties of each of the phases present and quite often different from the existing phases. An investigation of the interface elucidates the physical and structural knowledge of its atoms. The interfacial property is very important and frequently employed in a variety of engineering processes.

The liquid/ solid interface plays a fundamental role of great importance in diverse engineering fields and everyday life. [Hawang, et al 2010; Vasconcelos, et al 2010] It facilitates the understanding of catalysis, crystal growth, lubrication, electrochemistry, corrosion control and colloidal system in many biological reactions to mention a few. In summary, the interface phenomenon enhances surface chemistry [Lupescu, et al 1998)]

through the development of smooth surfaces with designed capability and improved performance for specific characteristic.

This is depicted by glass coating on steel that can be tailor -made for diverse engineering surfaces by the addition of appropriate ingredients. Glass coated surfaces are characterized by dimensional stability over a range of temperature and are optimized to have good mechanical strength and chemical resistance.

This paper investigates the nature of the bonding at the interface of glass coating on steel substrate that metamorphosed into diverse engineering surfaces employed. 


\section{Materials and Methods}

A glass frits composition was developed and obtained for the experiment based on calculation according to the Appen's formula in order to obtain the theoretical thermal expansion coefficient of glass adequate for a good adhesion on the steel support. [Marshall and White, 1986]. The batch composition of the raw materials developed for coating (ground coat) the base metal is presented on Table 1. Glass frits processing and preparation was made following the traditional method: weighing, milling. mixing, smelting and quenching. [Eppeler,1983]. The frits were prepared by wet process method and applied on a pretreated steel substrate - OL 140, Romanian standard and sintered in a furnace at temperatures range $780-900^{\circ} \mathrm{C}$. Cross sections of the coated samples were prepared and the nature of the occurring bonds evaluated using TEM, realized with TEM Joel 200 - CX microscopes, SEM (PHENON Pro X) and EDAX HIACHI S 2600Ndevice probes. The micrographs obtained are presented in figure $1-7$.

\begin{tabular}{|c|c|}
\hline Raw Material & \% Composition \\
\hline Feldspar & 36.30 \\
\hline Borax & 35.60 \\
\hline Sand & 14.60 \\
\hline Sodium carbonate & 7.40 \\
\hline Calcium Floride & 5.30 \\
\hline Cobalt Oxide & 0.20 \\
\hline Manganese dioxide & 0.60 \\
\hline
\end{tabular}

Table 1: Composition of Ground Coat Enamel

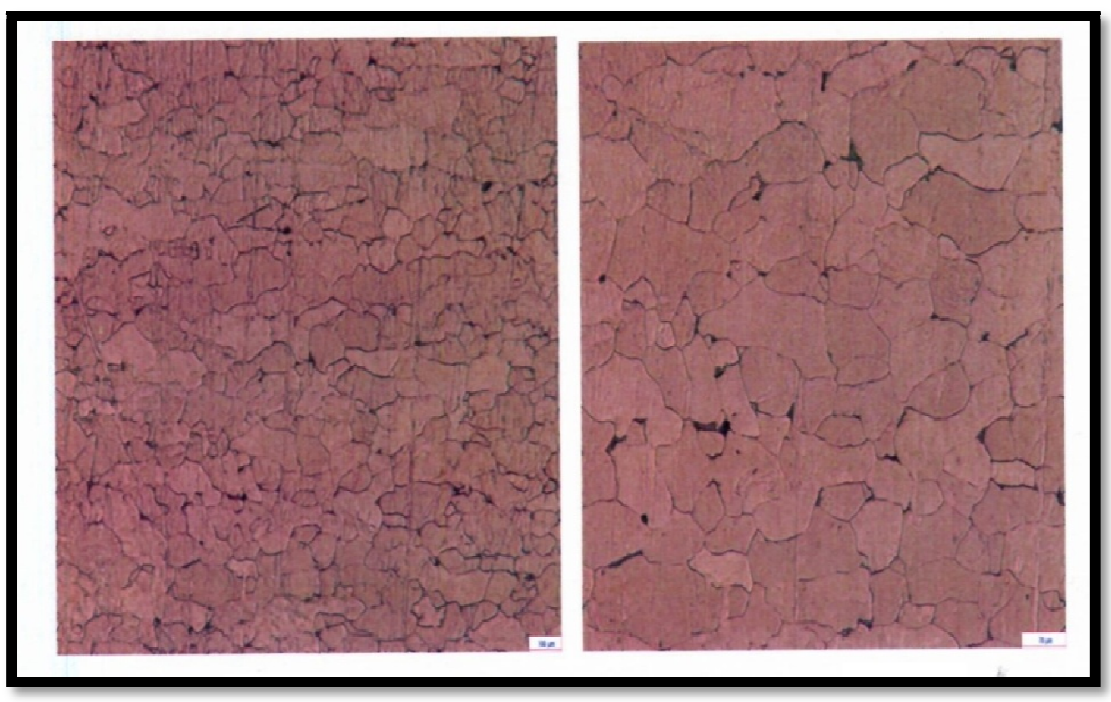

Figure 1: T. E. Micrographs-Cross Section of Sample Uncoated

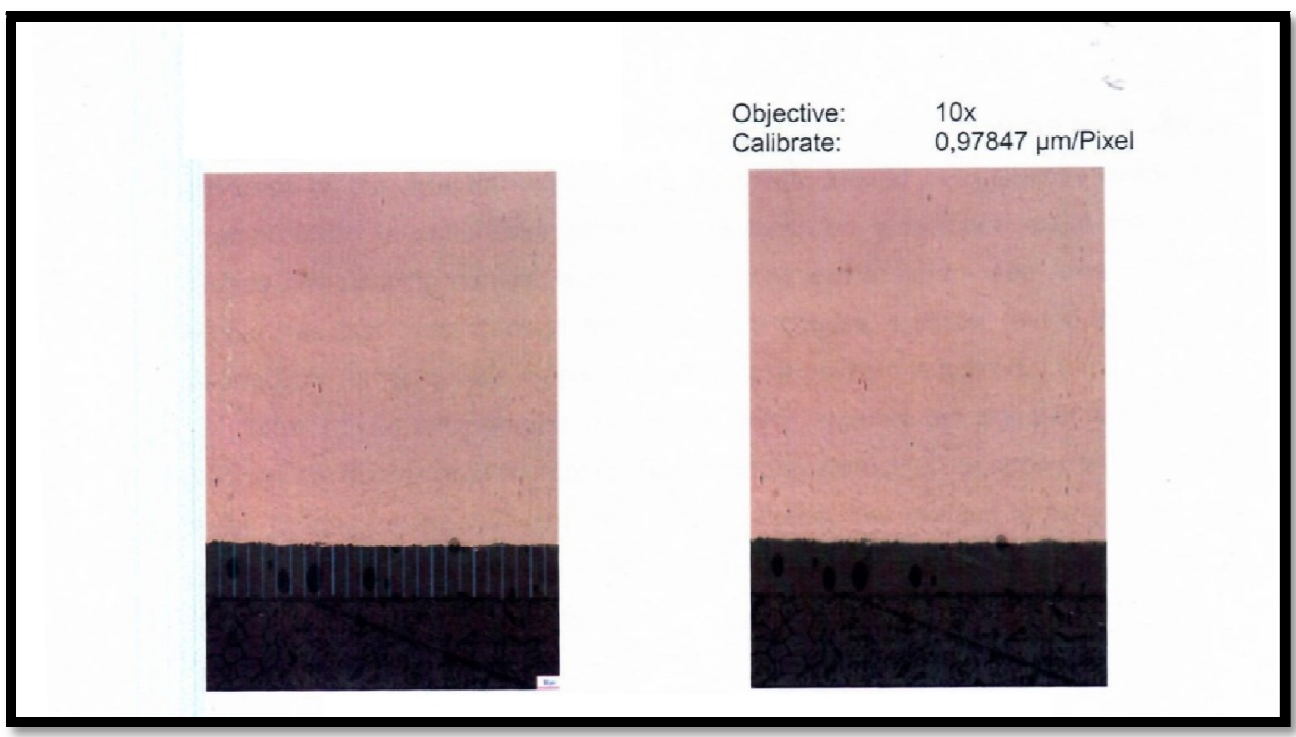

Figure 2: T. E. Micrographs-Cross Section Coated Sample with Few Bubbles 


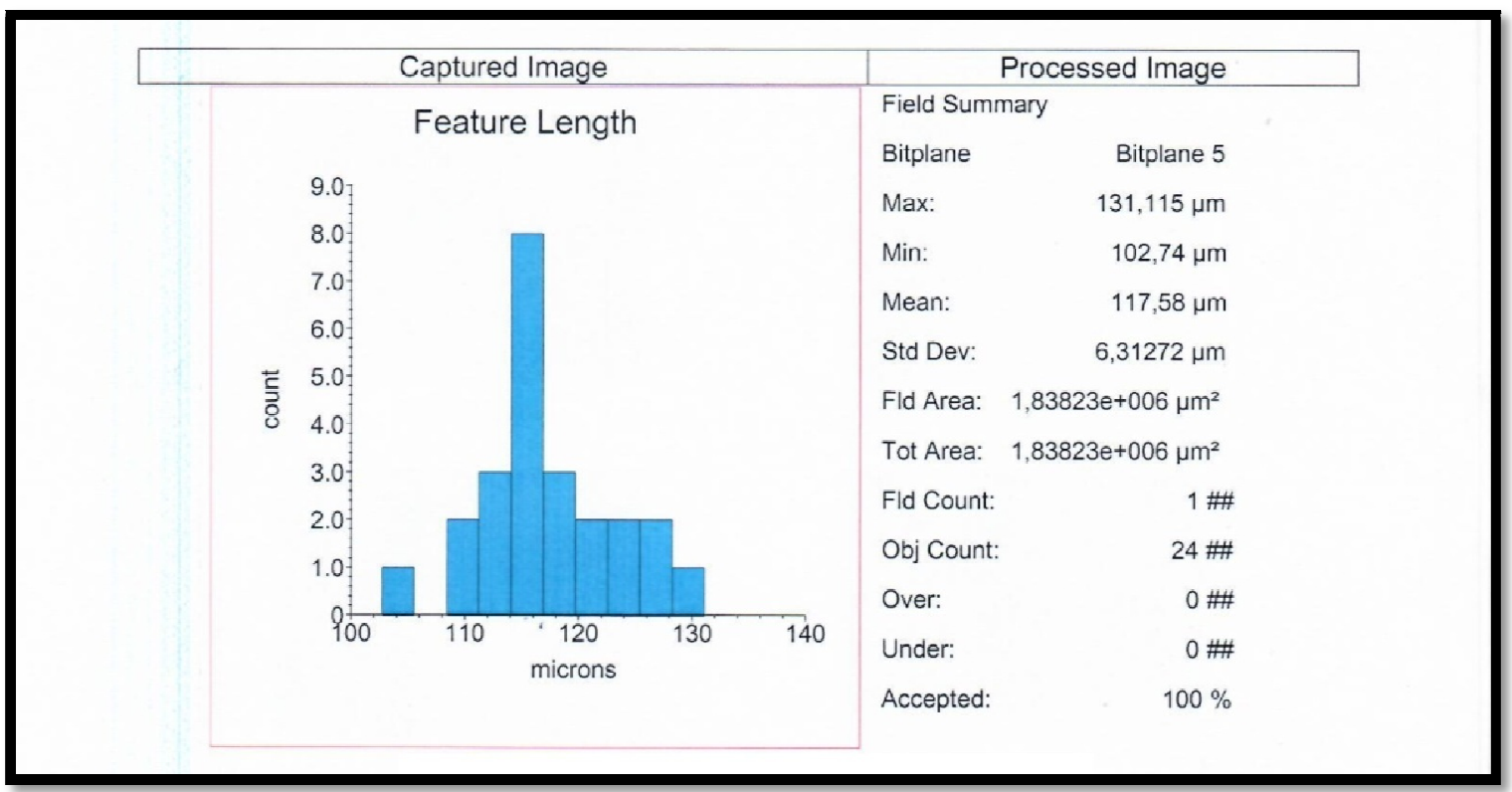

Figure 3: Particle Size Distribution on Metal-Enameled Interface Area

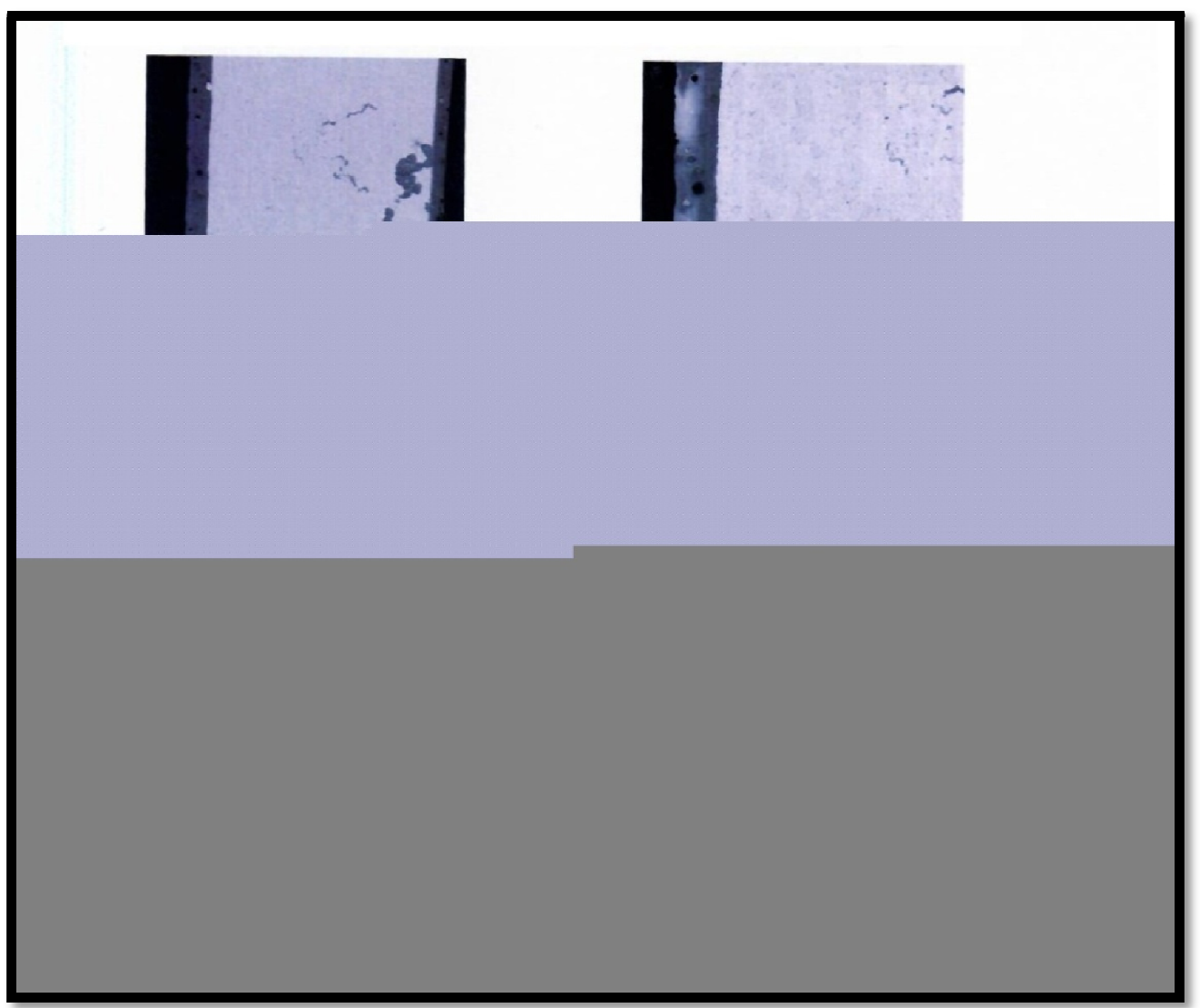

Figure 4: Present Surface Preview of Coated Sample at Different Magnitudes 


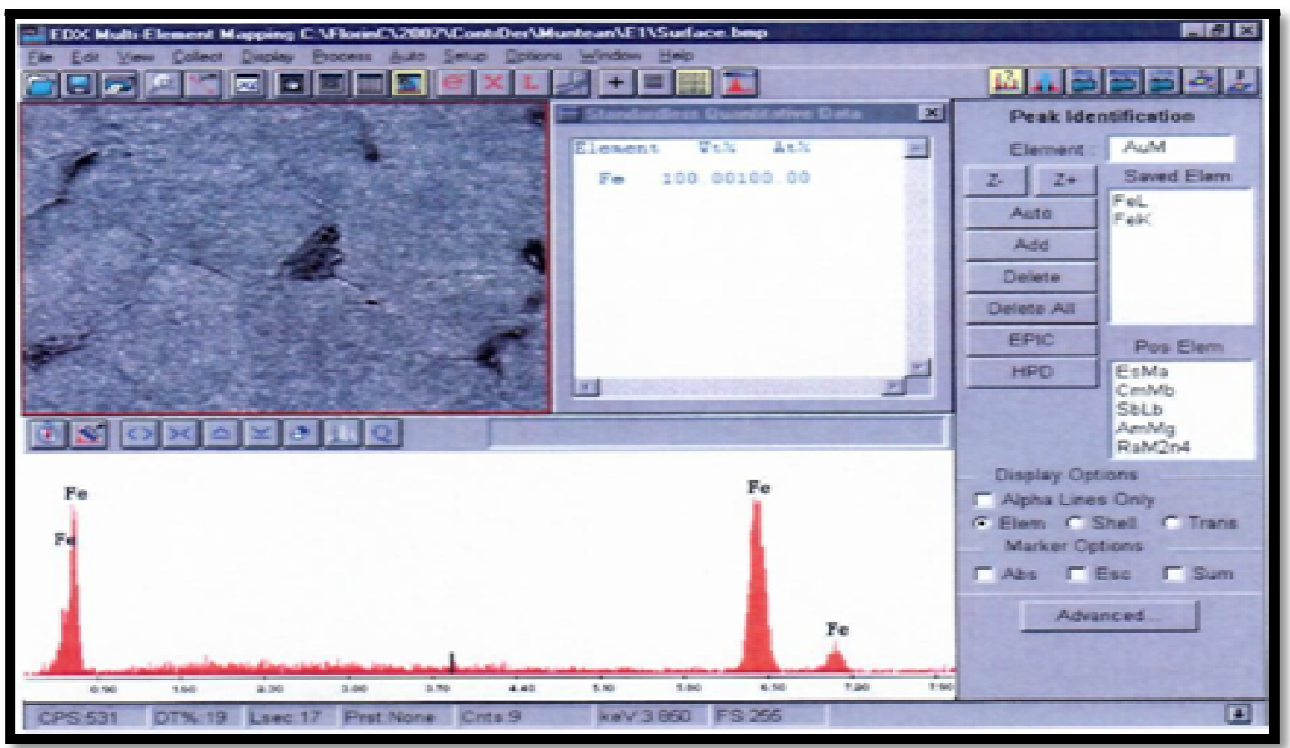

Figure 5: Fe Distribution at the Metal Matrix

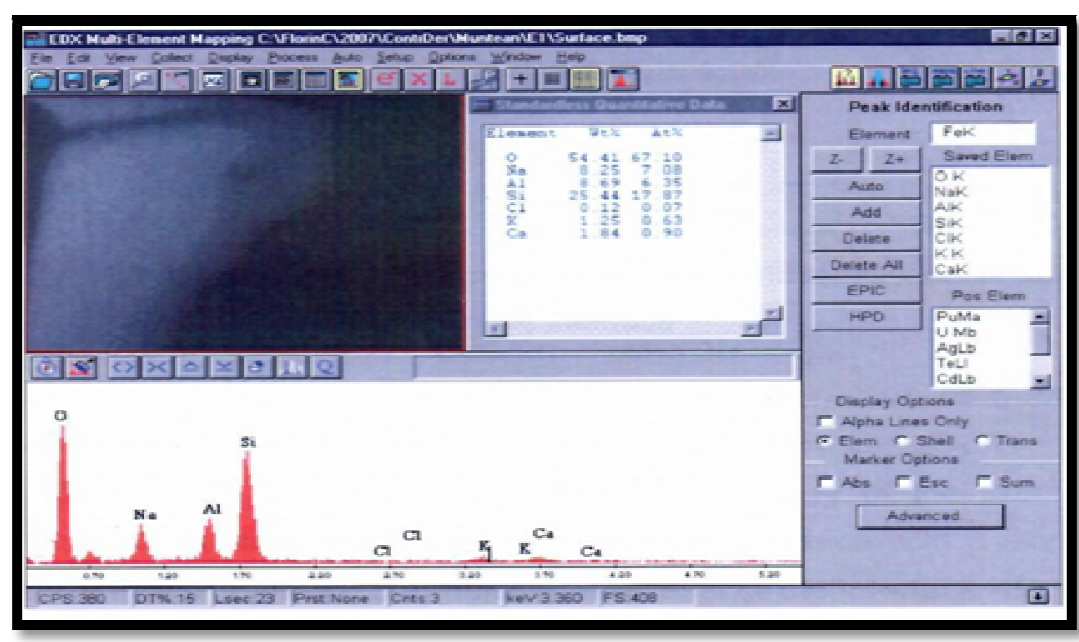

Figure 6: Si Distribution at the Coating Matrix

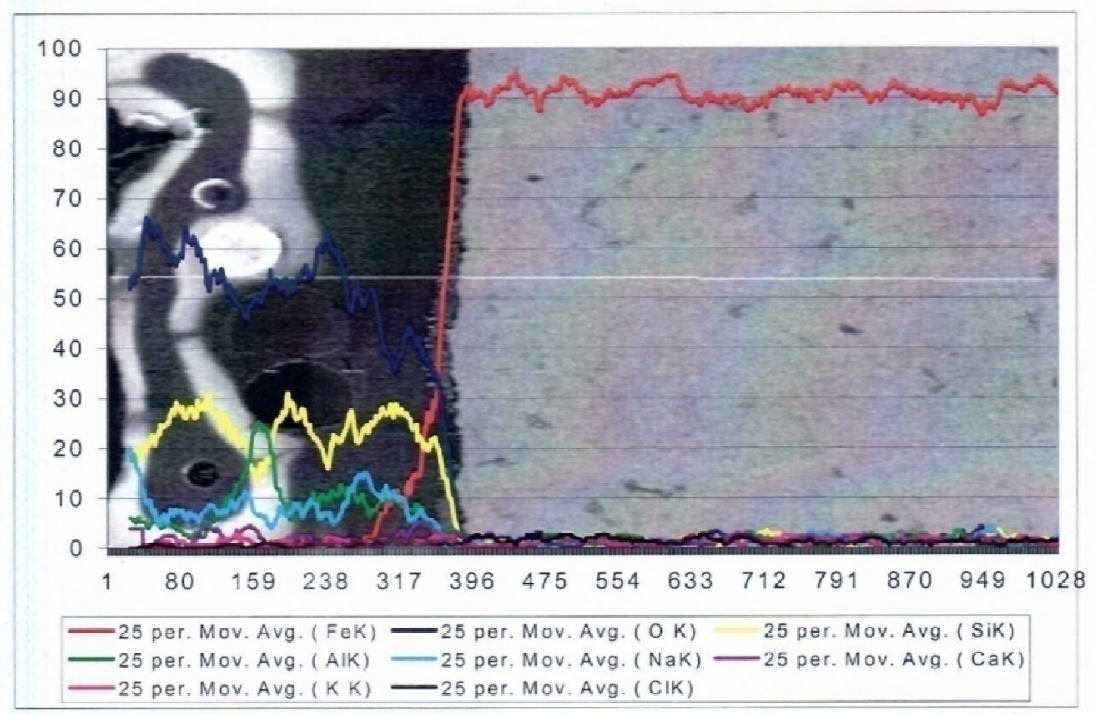

Figure 7: EDAX Elements Distribution at the Point of Bond Formation; Ceramic-metal Interface 


\section{Results and Discussions}

\subsection{Visual Observation}

The double-faced enameled samples obtained were observed to be glossy, impervious and having defect free surfaces.

\subsection{Transmission / Scanning Electron Microscopic Analysis}

Fig 1 presents TEM micrograph of uncoated steel sample with distinct grain boundaries. Fig.2 is the TEM cross sectional images of a glass coated steel sample. A very thin line of the interface layer is visible in the micrograph with few dark spots that seems to float on the interface layer. The dark spots could be attributed to the presence of air bubbles that are found in the interface region when the coating is under-fired. Scanning Electron Microscope (SEM) surface preview of the interface layer at different magnitudes, $5 \mu \mathrm{m}, 10 \mu \mathrm{m}, 20 \mu \mathrm{m} 50 \mu \mathrm{m} 100 \mu \mathrm{m}$ and $200 \mu \mathrm{m}$ are displayed on Fig, 4 . At $5 \mu \mathrm{m}$ magnification of the micrograph, the interfacial layer is discernable from the coating matrix and the metal matrix. The edge of the interface region is irregular at the point of contact with the steel substrate, with some areas protruded while some receded. This is ascribed to irregular surface of the steel support arising from pretreatment of the steel surface. This offers sites for physical bonding of the coating on the steel. Also, noticeable in this region are some whitish spots that are believed to be un-melted constituent of the glass composition. At $10 \mu \mathrm{m}$ magnification, the interface zone is quite distinct and the whitish spots are still apparent though smaller in size about $120 \mu$. The $20 \mu \mathrm{m}$ magnified sample displayed an enlarged size of the um-melted quartz and air bubbles seen as black spots on the specimen. The unevenness of the interface belt at the point of glass bonding to the steel section is still recognized. The enlarged repetitions of the images at $50 \mu \mathrm{m} 100 \mu \mathrm{m}$ and $200 \mu \mathrm{m}$ have similar features; however, the continuous uniform graded interface layer is more pronounced in these magnifications.

\subsection{EDAX Examination of the Interface Micrograph}

Fe distribution at the metal matrix is revealed in Fig 5, while Si distribution at the coating matrix is shown in Fig 6. $\mathrm{Si}$ and Fe are the major constituent elements that forms interface microstructure [Lampard, et al, 2018].

EDAX elements distribution at the point of interaction of glass and steel forming the interface is displayed on Fig 7, iron (red curve) silica (yellow curve), oxygen (blue dark curve), aluminum (green curve) sodium (blue curve).

A careful review of the elements distribution on the micrograph shows a good chemical interaction between the steel $(\mathrm{Fe})$ and the glass coating $(\mathrm{Si})$ at the interface. For example, the high concentration of Fe existing in the steel matrix is seen to take a plunge at the point of contact with the glass phase. This is a manifestation of a chemical interaction between the Fe and the glass phase. Similarly, the Si concentration plummeted at the point of contact with the steel matrix with a slope similar to that of Fe. The $\mathrm{Si}$ contour is a reflection of the Fe profile. The dissolution/ diffusion of Fe into the glass layer and that of $\mathrm{Si}$ into the steel phase demonstrate chemical interaction between the two matrices. [Lupescu, et al] This consequently may have generated bond formation / excellent adhesion of the coating material on the metal [Lupescu, (1997).] Indication of the strong chemical bond formation and excellent adherence of the coating material is also demonstrated by dominant convoluted areas in the interface with dendritic formations. This gives credence to the dendritic theory of mechanical bond formation basics of adhesion principle. [Takemori, 2009]. The concentration of other elements constituent of the glass phase followed the same trend. The content of $\mathrm{Al}$ (green colour) which is second to that $\mathrm{Si}$ in quantity in the coating matrix is seen to have decreased drastically at the interface region. Na (Light blue colour) also thinned out at the point of contact with interface layer. The amount of $\mathrm{K}$ (pink colour) in the coating layer is small, yet it dropped further at the interface zone and appears in patches in the steel region. Interestingly, the $\mathrm{O}$ (dark blue colour) concentration is seen to be low in the coating zone but increased in the steel zone. This increment is credited to the addition of $\mathrm{O}$ in coating matrix to $\mathrm{FeO}$ in the steel matrix. [Benjamin. et al, 1961]

\section{Conclusion}

The interaction of $\mathrm{Si}$ and $\mathrm{Fe}$ at the interface region signified that wetting, dissolution and diffusion have occurred at the interface ensuring adhesion. The outcome is a chemical reaction / bond formation between the coating and the metal substrate at the interface. Scanning electron micrographs and also EDAX analysis of the coated sample interfaces revealed continuous graded interface layer which made perfect contact with both the coating material and the metal substrate. Hence, the formation of chemical and mechanical bonded interface zone is responsible for the excellent performance and durability of glass coated steel surfaces. These attributes of the glass coated surfaces are greatly exploited and employed for engineering design capabilities for specific performance characteristics.

\section{Reference}

i. $\quad$ Hawes, M. K. (1986). “The Steel Industry: Change and Challenges” International J. Vol. 42. No.1. pp 25 -58

ii. Mailafia, O. O. (1998). "International Perspective on Iron and Steel Industry," National Conference of Nigeria Metallurgical Society Kuru - Nigeria

iii. $\quad$ Eppeler, R. A. (1986). "Glazes and Enamels" Advances in Ceramic Vol. 13.

iv. J. F. Mac Dowell and D Boyd. Ed. America Ceramic Society

v. Hwang, T, Lee, H, Kim, H, Kim, G. (2010). "Two layered Silicon Protective Film made by a Spray - and - Dip Coating Material on Stainless Steel”J. Sol- Gel Sci, Technical 55 (2), 207 - 212

vi. Vascoricelos, D. C. l., Carvallio, J.A.M., Mantel, M., and Vasconcelos, W. L. (2000). "Corrosion Resistance of Stainless Steel Coated with Sol-gel Silica” J.non-Crystal Solids, 273 (1), 135 -139 
vii. $\quad$ Lupescu, M., Zaharescu. M., Radu, D., Volceanov. A., (1998) "Surface/Interfacial Engineering and Adhesion in Metal Silicate Glass Systems ". Ceramic Congress, Eskisehir, Turkiye, p 791 - 796

viii. Marshall, K. A., and White, D., (1986). "Vitreous Enameling" A Guide to Modern Enameling Practice p. 10 Pergamon Press Oxford

ix. $\quad$ Eppeler. R. A., (1983) Glazes and Enamels, Publication: Glazes Science and Technology. Academic Press. Vol 1. P. $301-337$.

x. $\quad$ Lampard, F., Kalkhodaza, S., Kasama, T., Dahi, K. Brunn, V., C, Meiler, P (2018) “Probing the chemistry of Adhesion between a 316 Substrate and Spin on Glass Coating" Published by Langmuir

xi. Lupescu M and Zaherscu M. Interfacial Science in Ceramic Joining, Glasses and the Vitreous State, Part of the NATO ASI Series. Book Series, ASHI Vol 58 p. 357 - 364.

xii. $\quad$ Lupescu M. B. (1997). "Interface Phenomenon in Metal/ Glass Silicate Systems"

xiii. Doctorate Thesis. Institute of Physical Chemistry, Romania Academy, Bucharest. Romania

xiv. Takemori, M. (2009) "Crack Formation, Ex-foliation and Ridge Formation in 500'C. Annealed Sol-gel Silica Coating on Stainless Steel SUS 304; Part 1. Microscopic Observations / Elemental Analysis. Ceramic. International .35, $1731-1746$

xv. $\quad$ Benjamin, P. and Weaver, C. (1961) "The adhesion of Evaporated Metal Films on Glass" Proc. R. Soc London. Ser. A. Maths. Phys. 261 (1961) 516-531 